\title{
GEOGRAFIAS DO ARTISTA QUANDO COISA. MARCELO MOSCHETA E MANOEL DE BARROS COMO INTERCESSORES GEOGRÁFICOS
}

\author{
Wenceslao Machado de Oliveira Júnior ${ }^{1}$ \\ Gisele Girardi ${ }^{2}$
}

\section{Introdução}

Coisa... palavra bonita! Habitualmente a utilizamos quando não encontramos outra (talvez porque ainda não tenha sido inventada) para dizer aquilo que estamos pensando, ou sentindo, ou fazendo... Ela tanto pode funcionar como uma condição ou estado, como pode funcionar como um verbo. Aqui escapamos do uso dessa palavra pela tradição marxista, que atribui à "coisificação" a perda de valores, da "essência" e transformação em mercadoria. Interessa-nos a indiscernibilidade ou instabilidade daquilo que se quer expressar, apostando que é nesse movimento que a criação pode acontecer. Pois é esse o sentido com que Manoel de Barros em sua obra, mais especificamente no livro que inspira o título desse texto, "Retrato do artista quando coisa", nos brinda, e que Souza (2010) nomina de "poética do deslimite".

"Artista quando coisa", tanto pode remeter à condição de somente mais um ser no mundo, dentre tantos outros, e a compor vida com eles, como a um fazer que não é possível descrever com rigor, posto que híbrido, fluido. Devir. Nossa questão é como o artista, quando coisa, produz geografias e compõe com geografias. É preciso, então, de início, situar o trabalho com obras de arte como um "encontro de trajetórias até aqui" (Massey, 2008): a trajetória da obra como multiplicidade de trajetórias - do artista, das condicionantes institucionais, dos recursos materiais, da...; a trajetória do mirador da obra como multiplicidade de trajetórias - do corpo que olha, do pesquisador que estuda, da mãe que educa, da..., fazendo desse encontro o objeto da investigação, ou seja, uma trajetória funcionando como intercessores da outra, metamorfoseando-a.

Tomamos como intercessor, para compor pensamentos e argumentos sobre educação, linguagens e geografias, o artista Marcelo Moscheta, pois em sua vasta obra ${ }^{3}$ são recorrentes temas do escopo científico da geografia, como terra, fronteira, espaço, território, paisagem e também imagens cartográficas. A ciência funciona como intercessora para sua arte e vice-versa. Moschetta articula fazeres clássicos das mediações da ciência geográfica com o real na composição de suas obras: mapas, imagens de satélite, fotos de paisagens, perfis topográficos, coleções, trabalhos de campo. Tais fazeres são reconhecíveis e desestabilizados a um só tempo, aparecendo-nos abertos a outras possibilidades expressivas. É, portanto, nesse jogo de intercessores mútuos, entre ciência e arte, que buscamos matéria-prima para conversar sobre como hábitos geográficos-científicos, ao virarem matéria-prima de obras de arte, podem transtornar hábitos educativos e expandir as possibilidades para a Geografia, a partir das linguagens audiovisual e cartográfica.

Em outros termos, poderíamos perguntar: como trabalhar com obras de arte constituídas por e com linguagens imagéticas habituais da Geografia, e como fazê-lo sem esvaziar da obra sua potência poética, sem capturá-la nos esquemas representacionais/iconográficos que induzem a situar as imagens em Geografia somente no conjunto das fontes documentais?

Acompanhar o processo criativo de artistas e o pensamento sobre o espaço nele articulado pode nos dar pistas para algumas respostas ou, pelo menos (e talvez, melhor) expandir perguntas.

\footnotetext{
${ }^{1}$ Universidade Estadual de Campinas - UNICAMP. E-mail: wenceslao.oliveira@gmail.com.

${ }^{2}$ Universidade Federal do Espírito Santo - UFES. E-mail: gicele.cervi@gmail.com.

3 Cf. http://www.marcelomoscheta.art.br, http://galerialeme.com/artist/marcelo-moscheta/, MOSCHETA, M. Marcelo Moscheta. São Paulo: Ed. Bei, 2010 e MOSCHETA, M. Norte. Rio de Janeiro: Ed. Ímã, 2013.
} 


\section{Desrepresentar}

Mais do que negar ou significar uma privação, "des" expressa potencialização: um "transfazer" da coisa em outra.

Elton Luiz Leite de Souza acerca do prefixo "des" na poesia de Manoel de Barros

Faz algum tempo, alguns geógrafos e professores de geografia notaram na arte e nos artistas potências para o fazer e o pensar geográficos. Atualmente, as publicações que relacionam arte e geografia ${ }^{4}$ se multiplicam na medida mesma que as potências de funcionarem como intercessoras uma da outra se fazem mais nítidas entre os profissionais da ciência como já haviam se tornado entre os artistas ${ }^{5}$.

No caso dos autores desse texto, os intercessores têm sido, também, os autores da chamada Filosofia da Diferença, em especial Gilles Deleuze. O próprio conceito de intercessores nos chegou da obra desse filósofo, em parceria com Félix Guattari. Intercessores (sempre no plural) (Deleuze, 1992; 2007; Deleuze; Guattari, 1992) refere-se a corpos (humanos, não humanos, materiais, imateriais) em evolução a-paralela que, agenciados, entram em conexão. Intercessores andam ao lado, pois nunca seguem ou são seguidos, funcionam como aliados do estranhar-se e é assim que produzem um "entre" no qual se dá a criação. Ao trabalharmos com obras de arte e obras geográficas como intercessoras umas das outras, estamos a situar possibilidades de criação no "entre" estes dois termos.

Para Deleuze e Guattari (1992), há três caóides, ou filhas do caos, sendo o caos o infinito dos possíveis, e não uma desordem. Cada caóide corresponde a um modo do pensar: 1. a filosofia cria conceitos, a partir de variações, atravessando o caos; 2 . a ciência cria funções, a partir de variáveis, recortando o caos e 3; a arte cria agregados sensíveis, por meio de variedades, perpetuando o caos. Daí que são como intercessores e não como substituições que esses modos de pensar afetam uns aos outros.

A criação de agregados sensíveis, por artistas, comporta uma infinidade de possibilidades técnicas, conceituais, conjunturais, etc. A poética da obra, no entanto, está em fazer com que nada se estabilize (esse é o sentido da perpetuação do caos) e sempre se abram, através dela, novos possíveis. O entendimento do processo criativo de artistas, das forças que atuaram e que mobilizaram na criação de obras que, por sua vez, tomaram produtos da ciência como suas matériasprimas, e como foram se dando os tensionamentos nesse "entre", é o que nos interessa. A aposta é que obras de arte que tomaram produtos da ciência, no caso a "geográfica" e a "cartográfica" como elemento de composição, podem produzir acasos manipulados, obrigando o pensamento científico (geográfico) a mover-se, a pensar na diferença (em outras políticas e poéticas espaciais?).

\footnotetext{
${ }^{4}$ É notória a ampliação, nos últimos anos, de trabalhos em eventos científicos da Geografia que abordam a relação da geografia com a arte, ainda que neles se observe certa tendência de captura das obras de arte como fonte documental. Ainda são mais comuns trabalhos com a literatura (romances, poesias, letras de música) e com pinturas de paisagens. Sugerimos consultar as produções dos eventos "Geografia, Literatura e Arte", "Simpósio Espaço \& Cultura" e "Colóquio A Educação pelas imagens e suas geografias", bem como Grupos de Trabalhos específicos nos eventos "Encontro Nacional de Geógrafos", "Encontro Nacional de Prática de Ensino da Geografia" e "Encontro Nacional da Associação de Pós-Graduação em Geografia".

${ }^{5}$ A título de exemplo, citamos o coletivo de artistas participantes da $8^{\text {a }}$ Bienal do Mercosul, que teve como tema "Ensaios de Geopoética" (Bienal do Mercosul, Porto Alegre-ES, 2011) e as exposições ou mostras coletivas: "Por aqui" (Galeria Vermelho, São Paulo-SP, 2009); "Geografias - Antologia de Omissões e Desvelos" (Sesc, Jundiaí-SP, 2016) "Tempo, Espaço e Lugar" (MACC, Campinas-SP, 2016); "Geografia do atopos" (Galeria Alfinete, Brasília-DF, 2016); "Geografias - nosso lugar é o caminho" (Sesc, Santos-SP, 2017); "Imaginar Geografias" (Sesc, Vitória-ES, 2016).
} 
Acaso manipulado é uma ideia apresentada por Deleuze (2007) no livro "Francis Bacon: Lógica da Sensação", quando este toma a obra de Francis Bacon, acompanhando as forças que atuaram nos processos criativos do artista, fazendo delas intercessoras de seu pensamento filosófico. A estratégia de "acaso manipulado" de Francis Bacon é considerada por Deleuze como meio de limpar a tela em branco, como meio de escapar dos clichês já postos antes mesmo do pintor começar a pintar. Tais clichês podem ser entendidos como a força do representacional ou do decalque, ideias sedimentadas, que criam limitações para a emergência do novo. Para fugir das imagens já presentes antes de pintar, por exemplo, um rosto, Francis Bacon "chicoteava" a tela em branco com uma toalha embebida em tinta. Esse "acaso" (as marcas da tinta) é que definia onde, por exemplo, estariam os olhos, obrigando-o a reinventar modos de pintar rostos. Esse traço do processo criativo de Francis Bacon, Deleuze converte em potências para o produção de conceitos fillosóficos. Obrigar o pensamento a pensar com a diferença é que faz, para Deleuze, a arte funcionar como intercessores da filosofia.

Em nosso caso, a arte produzida com elementos do universo discursivo e prático da geografia funciona como "acaso manipulado" na medida em que a tomamos como ponto de partida para deslocar e desestabilizar o pensamento científico. Assim, mirando para os intercessores ciência e arte, podemos tomar obras de arte compostas com traços do universo da ciência para expandir os próprios limites da ciência. É nessa perspectiva que abordamos processos e obras do artista Marcelo Moscheta como intercessores para pensarmos as práticas geográficas da representação do espaço através de duas linguagens muito frequentes na Geografia: a cartográfica e a audiovisual. O modo que esse artista lida com essas duas linguagens, força-nos a entrar em contato com aquilo que podemos chamar de desrepresentação do espaço, tomando Manoel de Barros como filósofo que nos deu o conceito de "des", o qual pode ser visto operando no final de seu poema Retrato do artista quando coisa.

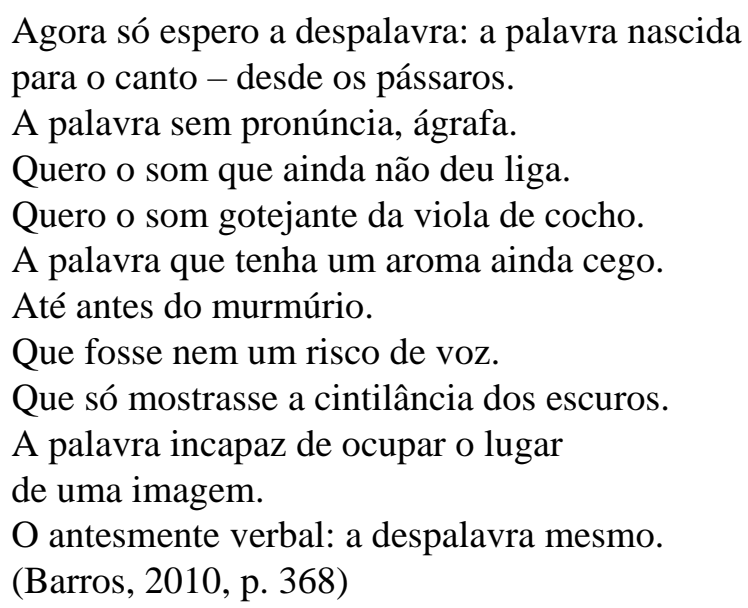

A seguir buscaremos apontar como essa desrepresentação opera na obra de Marcelo Moscheta em seu enfrentamento com os lugares e como esse processo pode nos abrir possibilidades para transtornar hábitos educativos na geografia.

\section{$O$ artista quando coisa geográfica ou o artista quando coisa geografias}

Numa entrevista acerca da Exposição Norte ${ }^{6}$, realizada em 2012 no Rio de Janeiro, Marcelo Moscheta diz: "Eu quero ter um enfrentamento com o lugar, e quero que esse lugar me traga

\footnotetext{
${ }^{6}$ https://www.youtube.com/watch?v=QORCKUHz4B0.
} 
dúvidas”. Esse modus é reafirmado em um texto do artista produzido para um catálogo 7: "Quero, assim, abarcar todas as possibilidades de entender um local, não somente por meios sensíveis, como o desenho ou a fotografia, mas através de formas racionais de se entender o Lugar: latitude, longitude, altitude, cálculos matemáticos e referências técnico/científicas". Esse artista tem os lugares e referenciais científicos da Geografia como intercessores de sua obra, principalmente aqueles muito distintos daquele em que vive ${ }^{8}$, como o arquipélago Svalbard que "é o ponto da Terra permanentemente habitado mais próximo do Polo Norte" , onde esteve por três semanas numa residência artística em 2011, ou o deserto de Atacama, onde esteve por dez dias em residência artística em 2012, no âmbito do projeto "Plataforma Atacama: arte y lugar"10".

No primeiro parágrafo de sua "biografia oficial" pode-se ler:

Um fio condutor na obra de Moscheta é a grande fascinação que tem pela natureza, assim como a sua disposição aberta à viagem e o enfrentamento com os elementos retirados da paisagem. Essa experiência de viajar e conviver em ambientes agrestes despertou seu interesse em retratar a memória de um lugar, elaborando um procedimento de classificação similar ao arqueológico e que questiona, por meio da arte, as fronteiras do território, da geografia e da física. ${ }^{11}$

Essa breve apresentação visa colocar diante dos leitores um artista que tem seu percurso de criação atravessado por muitas práticas e preocupações que são também geográficas. Seu processo de criação tem sido, cada vez mais, deixar-se solto para os encontros inusitados nos lugares, aquilo que o faz deter-se em algo, como se ali se desse uma espécie de contágio com aquilo que o estranha e surpreende. Nesse sentido, a criação associa-se a uma certa perda do controle. Ao comentar sobre isso Marcelo Moscheta diz que gosta cada vez mais de ter

A oportunidade de me colocar em situações em que eu não tenha o controle, uma falta de controle planejada, justamente para ser o contrário do ateliê; porque o ateliê é esse lugar onde tudo tá no seu lugar, tá tudo aqui, tudo arrumado. E isso tem me deixado cada vez mais aflito de ter o controle dessas coisas, tô buscando uma coisa até mais orgânica, mais solta, mais livre... ${ }^{12}$

E completa dizendo:

Quanto mais eu tenho feito essas incursões para fora do ateliê, mais tenho gostado do que o lugar me propõe; mais tenho me interessado por perder esse tipo de controle. Ficar realmente numa situação onde o lugar possa me dizer, porque pra mim o mais interessante é isso. [...] O que me traz uma felicidade grande como artista, como criador, é quando aquilo que você tá fazendo consegue criar um diálogo com você e te falar o quê que... qual o caminho aí. ${ }^{13}$

\footnotetext{
${ }^{7}$ http://www.marcelomoscheta.art.br/Anotacoes-Sobre-Desejos-Classificatorios-e-Outros-Incomodos-criativos.

${ }^{8}$ Marcelo Moscheta mora em Campinas-SP.

${ }^{9}$ https://pt.wikipedia.org/wiki/Svalbard.

10 www.plataformaatacama.org/.

${ }^{11} \mathrm{http}: / / \mathrm{www} \cdot \mathrm{marcelomoscheta.art.br/BIO}$.

12 Trecho da entrevista realizada por Gisele Girardi e Wenceslao Machado de Oliveira Júnior, em 25 de outubro de 2013, no ateliê do artista em Campinas-SP.

${ }^{13}$ Trecho da entrevista realizada por Gisele Girardi e Wenceslao Machado de Oliveira Júnior, em 25 de outubro de 2013, no ateliê do artista em Campinas-SP.
} 
Apesar das muitas semelhanças com os Trabalhos de Campo da formação científica em Geografia ou com os Estudos do Meio da formação escolar nessa disciplina, o encontro com o lugar se dá justamente quando o artista perde o controle, quando o lugar se impõe como algo que surpreende e propõe um novo olhar, um reparar nalgum detalhe que faça o corpo do artista vibrar de uma maneira inusitada, seja exigindo paradas e contemplações, seja suscitando uma ínfima ação naquele lugar, sutilmente transformando-o em outro (ainda que provisoriamente). Nos dois casos o lugar não é tomado como algo que é externo ao humano - como é habitual ocorrer nos Trabalhos de Campo e Estudos do Meio, quando vai-se até um lugar para conhece-lo, descobrir como ele é, como algo já dado antes do humano que ali chega -, mas sim como algo que afeta o corpo (humano?), configurando-o, assim como o lugar é configurado por ele (humano e inumano). Em outras palavras, Marcelo Moscheta se expõe aos lugares para deles extrair singularidades que passam a existir justo no encontro entre artista e lugar. Como pergunta geográfica e educativa que se desdobra, não seria interessante que nos Trabalhos de Campo e Estudos do Meio fossem exploradas não somente as regularidades das experiências vivenciadas em cada lugar, mas também as singularidades que se configuraram nesse encontro? Tomar como matéria prima do conhecimento acerca do espaço também as diferenças que cada corpo apresenta ao expor-se a um lugar, bem como as sutis diferenças que cada lugar incorpora ao suscitar pequenas ações em cada corpo?

Para além das potencialidades para a educação geográfica que encontramos no próprio processo de criação desse artista, apresentamos as potencialidades que as obras criadas por Marcelo Moscheta podem assumir quando tomadas como possíveis grafias do espaço, geografias compostas por descartografias e desaudiovisualidades.

\section{Descartografar}

No que se refere especificamente aos mapas, Moscheta nos informou ${ }^{14}$ que sempre tivera um fascínio por mapas. Tem uma coleção deles (seu ateliê dispõe de várias mapotecas) e fez muito uso deles para o planejamento da execução de obras de arte. Contudo, só muito recentemente descobrira que mapas eram também invenções, interpretações sobre lugares e não os lugares traduzidos no papel, e que comportariam poéticas. Isso o que o instigou não só a usar os mapas em sua função ordinária (localização, marcação de rotas, etc.), mas, também, a criar obras a partir deles. "Void" e "Potências de 10" são exemplos de como o universo científico da cartografia (mapas e seus elementos) foi articulado pelo artista na composição de suas obras.

Em "Void" 15 , a criação implica em recortar da cópia heliográfica de um mapa topográfico todas as denominações, os topônimos, os textos de legenda, título, etc. O mapa é colado em uma superfície metálica e, portanto, reflete, nos vãos onde antes se situavam as palavras, a imagem do observador da obra. Moscheta cala o mapa ao eliminar dele as denominações, desfamiliariza o leitor com o sentido de mapa já-dado e o faz parte do mapa, faz com que habite o mapa por meio de fragmentos de reflexos seus. O mapa está lá, mas aberto a outros sentidos possíveis. Provoca o pensamento a pensar nas denominações como forças de estabilização e controle dos lugares, seja o controle político (aqui é), seja o controle científico.

Na obra "Potências de 10"16, são tomadas e desestabilizadas as noções de escala e de tecnologias de visualização. O artista fotografa cenas ordinárias (uma pequena área de uma calçada de pedra, uma mancha de café no chão da cozinha...), trata-as com zooms, filtros e lhes atribui escalas crescentes em potências do sistema métrico decimal (1:1;1:10;1:10.000 etc.).

\footnotetext{
${ }^{14}$ Entrevista concedida pelo artista a Wenceslao Machado de Oliveira Júnior e Gisele Girardi, em seu ateliê de Campinas-SP, em 25 de outubro de 2013.

15 https://daniname.wordpress.com/2010/10/19/pipa-marcelo-moscheta/.

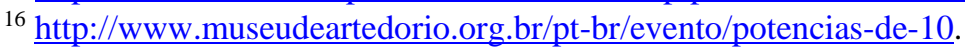


A obra, um tabloide impresso, nos chega como um atlas que, ao mesmo tempo em que nos assegura a distância da qual estamos vendo (o referencial de escala), promovendo um deslocamento horizontal (à semelhança do que é trabalhado no vídeo "Power of ten"17, que inspira a obra), tira-nos completamente a certeza do que vemos. Um olho-cérebro de geógrafo treinado em leituras de imagens aéreas (orbitais ou não) comumente buscaria na imagem padrões, texturas, etc., que indiciassem algum "lugar real". Padrões e texturas estão lá na obra a seduzir justamente para esse movimento de descoberta, sem, contudo, dar qualquer certeza que permita que se afirme que "lugar real" seria esse. Essa é a força da obra: desafiar o que vemos com as tecnologias do olhar, arrastando para a desestabilização todas as certezas sobre o espaço com as quais nos habituamos ao olhar imagens aéreas.

Esses são breves exemplos dos modos como Moscheta cria descartografias, já explorados em outros escritos (Girardi, 2013; 2014). Nesse texto, exploraremos mais detidamente obras da exposição "1000 km, 10.000 anos", fruto da residência do artista no âmbito do Projeto Plataforma Atacama: Arte y lugar, realizada em 2012.

A residência de dez dias no deserto de Atacama significou o enfrentamento do artista com o lugar. "As condições tanto geográficas como arqueológicas e astronômicas com as quais conta esta paisagem o incentivaram a desenvolver uma obra que estabelece a comunicação entre o aqui e o infinito a partir de uma perspectiva histórica" (Tala, 2013). $1000 \mathrm{~km}$ foi a extensão percorrida nos deslocamentos feitos pelo artista na região, registrada em mapa (Figura 1). Na medida em que usa o mapa para registro de rotas e nele insere anotações que se reportam a ideias, memórias, etc., transforma o mapa, a um só tempo, em dispositivo do extensivo (a distância percorrida) e do intensivo (a experimentação do/com o lugar). Deslocamentos intensivos e extensivos que se imbricam na composição de pensamentos que vão municiar a criação e a produção das obras.

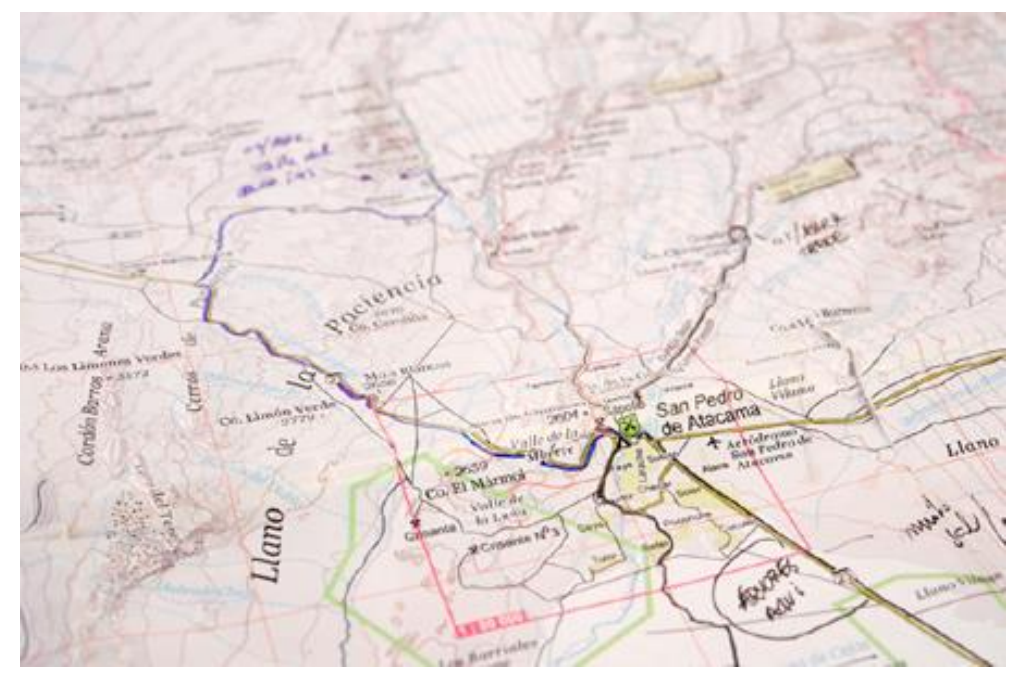

Figura 1 - Fonte: http://www.plataformaatacama.org/galeria_moscheta/mapa1.jpg

Nessa experiência com o lugar, Moscheta toma contato com artefatos arqueológicos, ferramentas paleolíticas datadas de 10.000 anos atrás, indicando a extensão temporal da relação de grupos humanos com aquele lugar. Do mesmo modo que o artista, habitante contemporâneo do mundo, recebeu pistas da relação de grupos humanos do passado com o lugar, ele se incumbe, também, da tarefa de deixar pistas para quem, no futuro, habitar esse mesmo lugar

\footnotetext{
${ }^{17}$ Filme de Ray e Charles Eames, de 1977. Disponível em: 〈http://www.powersof10.com/film〉.
} 
(BUENAVENTURA, 2013). Isso é efetivado por meio de uma instalação no local, tomando a noção de latitude, conceito do universo habitualmente entendido como geográfico, como articuladora. Moscheta empilhou rochas das proximidades, em um alinhamento de 15 metros, exatamente na marca do Trópico de Capricórnio, paralelo notável que marca o limite sul da zona tropical, o solstício de verão no hemisfério sul. Por essa característica, a instalação local, para ser compreendida, demandaria um tempo longo de observação: implicaria habitar o lugar, pois somente em um dia do ano o empilhamento não produziria sombra, exatamente no dia do solstício, quando a incidência dos raios solares é perpendicular ao alinhamento no qual as rochas foram arranjadas. (Figura 2).

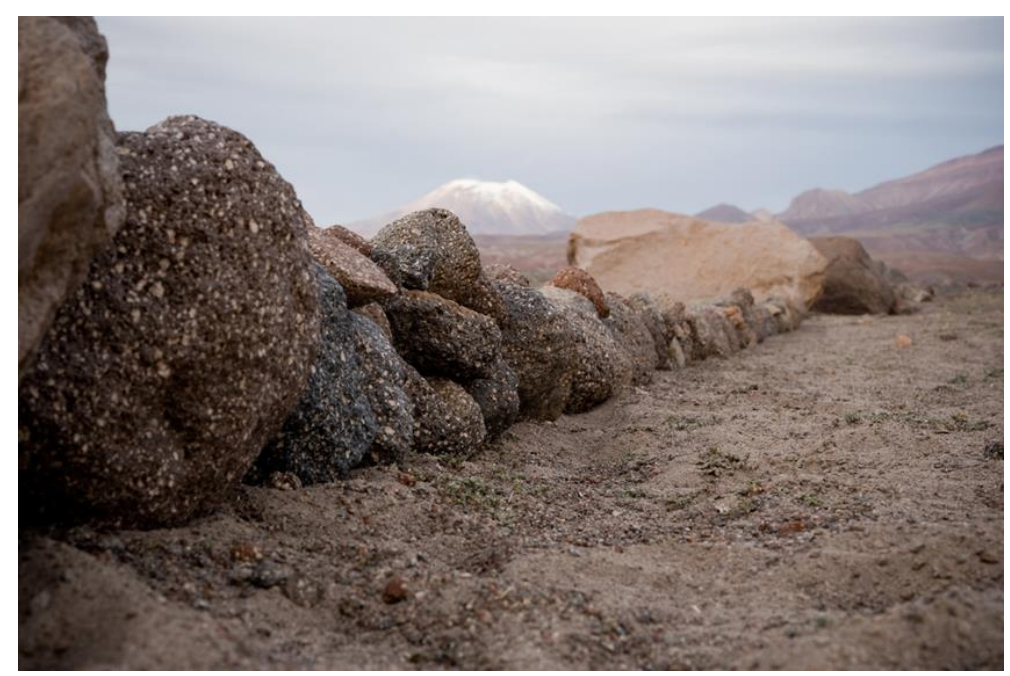

Figura 2 - Fonte: Fotograma do vídeo disponível em: http://www.plataformaatacama.org/proyecto_marcelo_moscheta4.php

Os deslocamentos, no espaço-tempo, traduziram-se no enfrentamento de Moscheta com o lugar Atacama, convergindo para a composição da exposição "1000 km, 10.000 anos". De início nota-se a recorrência dos referenciais científicos e objetivos no próprio título da exposição, que, assim como na obra "Potências de 10", enfatiza números exatos com os quais nos habituamos a pensar a partir da adoção ampla, em nível mundial, do sistema decimal como parâmetro para medidas de espaço (sistema métrico), de tempo em nível macro (década, século, milênio), e muitos outros. Outra pista que o título indica é a das variáveis tempo (anos) e espaço (km) absolutos. Se de início essas notações fornecem um referencial seguro, rapidamente são desestabilizadas.

É sabido que o pensamento analítico torna-se mais e mais cego para a totalidade do contexto quanto mais se aprofunda na tarefa de nomear e estruturar partículas menores e mais recortadas da realidade concreta Marcelo Moscheta não corrige essa miopia, mas se aproveita dela para trapacear no jogo do pensamento moderno e criar suas máquinas de sonho presente (MYIADA, 2015).

A exposição "1000 km, 10.000 anos" é composta por três obras desdobradas das experiências do artista na residência do Plataforma Atacama: "Linha:Tempo:Espaço", "Timelapse" e "Atacama: 28.04-06.05/2012" (Figura 3). 


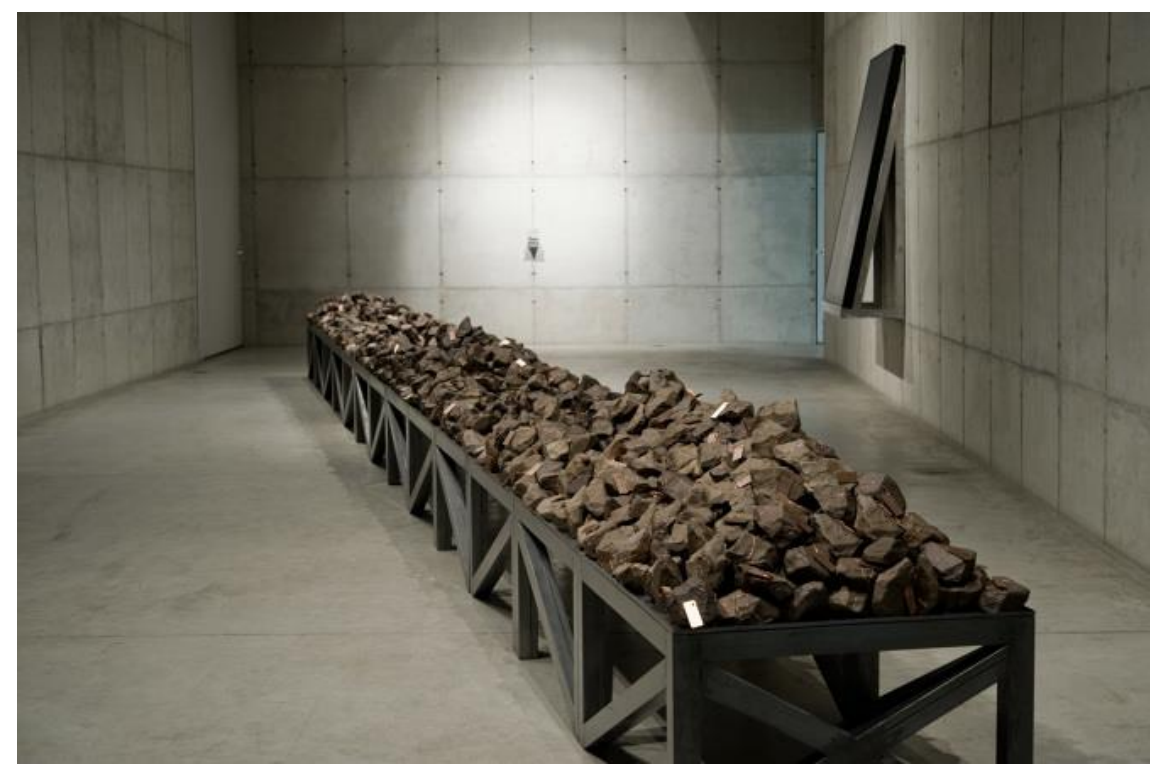

Figura 3 - Fonte: http://payload505.cargocollective.com/1/22/731896/12402058/atacama04_1920_670.jpg

Em Linha:Tempo:Espaço, o artista simula a recriação do alinhamento de fragmentos de rocha realizado no Atacama. No entanto, em vez de rochas, o alinhamento é feito de cópias em cerâmica de uma das ferramentas paleolíticas encontradas no local. São 2500 peças idênticas, cada uma delas amarrada a uma etiqueta de cobre com latitudes e longitudes dos pontos que compuseram a rota de deslocamento do artista pelo deserto de Atacama (Figura 4).

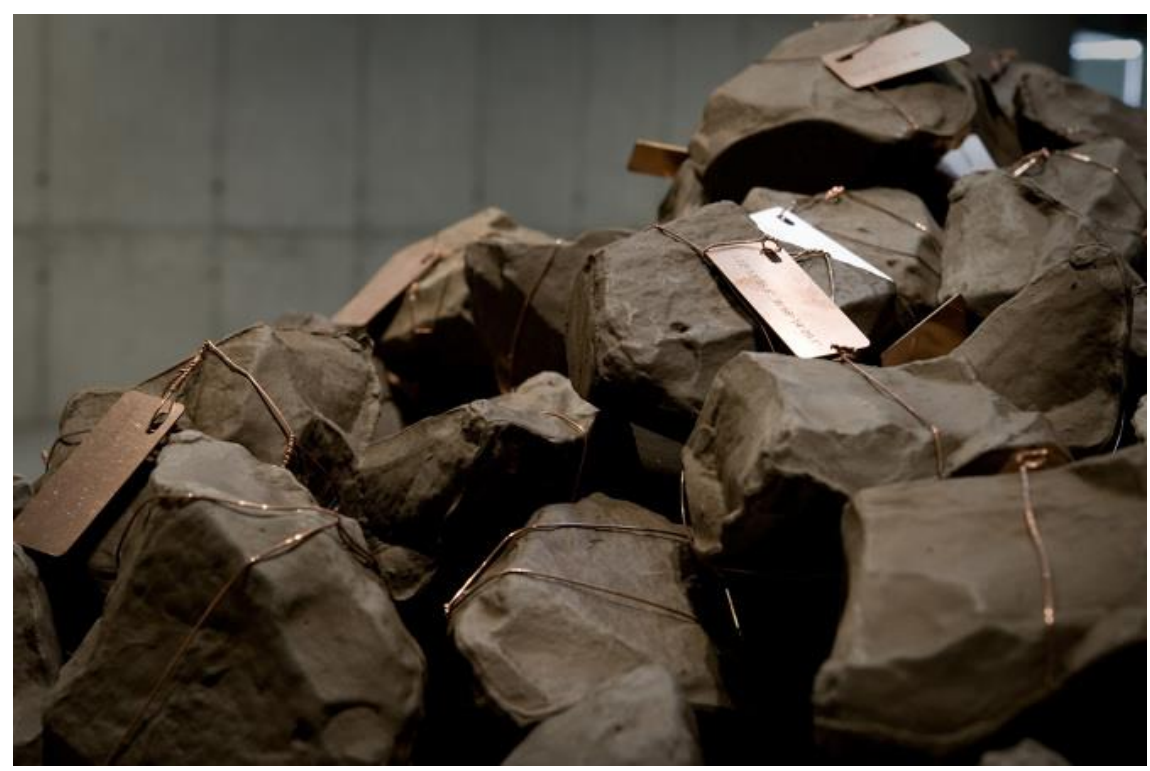

Figura 4 - Fonte: http://payload505.cargocollective.com/1/22/731896/12402058/atacama05_1920_670.jpg

Timelapse (Figura 5) é constituída por uma pequena caixa metálica contendo solo e fragmentos de rocha do deserto, fechada com uma tampa acrílica com gradações decimais nas bordas, acompanhada por um mapa-mundi (dois hemisférios), pela data que marca a passagem dos primeiros habitantes naquele lugar (10.800 B. C.) e pelos dizeres "Here men from the Planet Earth first set foot upon the Earth. We came in peace for all mankind". Segundo a curadora da exposição, a obra "estabelece uma comunicação entre o passado, por meio das pegadas dos primeiros habitantes desta terra, e o futuro, visto através da observação das estrelas como uma espécie de ponte entre o ontem e o amanhã, guardado, selado e registrado, desta vez pelo artista" (TALA, 2015). 


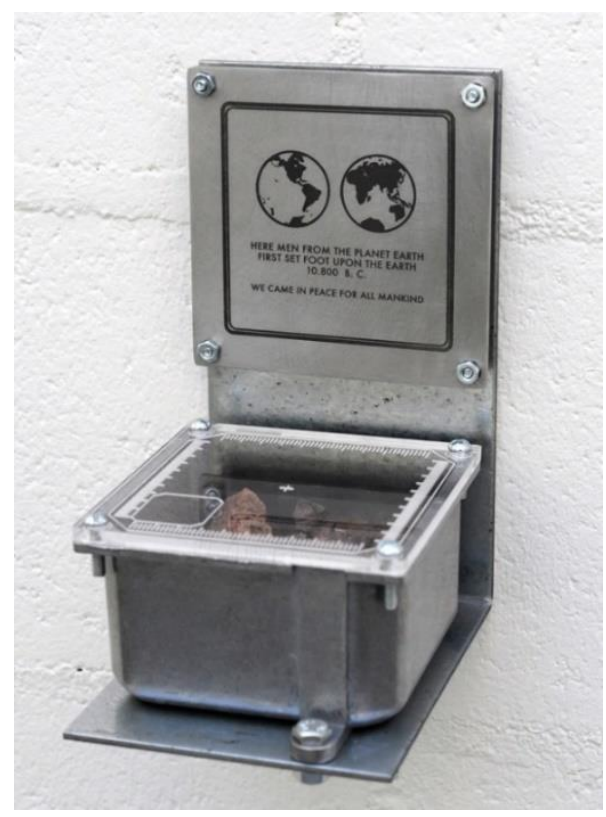

Figura 5 - Fonte: http://payload507.cargocollective.com/1/22/731896/12449094/atacama12_1920_654.jpg

Finalmente, Atacama: 28.04-06.05/2012 é um mapa que visa apresentar a rota do deslocamento pelo deserto. O mapa é realizado com uma técnica desenvolvida pelo artista que é a cobertura de uma placa de PVC com grafite e criação de texturas, sombreamentos e outros elementos habituais em fotografias aéreas, com uso de borrachas. Ou seja, a obra é produzida não por inclusão de coisas (traços, formas, elementos gráficos), mas por apagamentos (Figura 6).

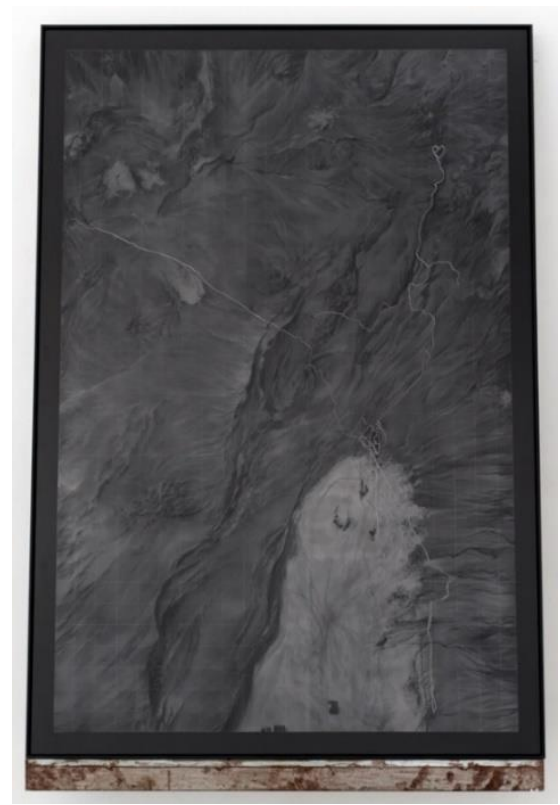

Figura 6 - Fonte: http://payload507.cargocollective.com/1/22/731896/12449178/SK2A1697edt-Ricardo-Miyada_640.jpg

Tanto nas atividades desenvolvidas durante a residência como na composição das obras que dela decorreram, é notável como o artista toma os referenciais geográficos-cartográficos como intercessores, em especial, aqueles habitualmente atribuídos à cartografia (mapas, paralelos, coordenadas geográficas, imagens aéreas). A aproximação com o processo criativo de artistas que compõe obras com elementos do universo geográfico-cartográfico é um caminho metodológico possível para lidar com arte e geocartografia, tomando-os como intercessores uns 
dos outros. "Com" a obra e seu processo de criação buscamos pistas sobre como a imagem cartográfica compõe o imaginário espacial - portanto político - de artistas e como estes, ao se apropriarem de linguagens para falar do espacial, colocam essas mesmas linguagens sob tensão.

O entendimento do processo criativo das obras de Moscheta que compuseram a exposição "1000 km, 10.000 anos" nos provoca pensar algumas perguntas para a geografia e a educação, mais precisamente para o campo amplamente reconhecido como "cartografia escolar". Esse campo é, em geral, carregado de prescrições, de sentenças tais como "o mapa é" ou "o mapa tem que ter”. Dentre estas, as coordenadas geográficas, as localizações absolutas. Na obra "Linha:Tempo:Espaço", Moscheta toma essas noções como matéria-prima, materializa uma fração da linha imaginária Trópico de Capricónio por meio de empilhamento e alinhamento de rochas in loco, e recria o alinhamento em galeria. Na galeria de arte, assim como em qualquer mapa, aquilo é e não é o Trópico de Capricórnio. Faz as vezes de, mas não carrega o mesmo sentido do que a instalação no próprio Atacama.

O que mais, no mapa, é descolado da experiência do habitar para ser uma reprodução de prescrições, mesmo que essa intencione subsidiar a produção de outros conhecimentos? As peças que compõem o fragmento do Trópico de Capricórnio recriado na galeria são idênticas em sua forma e material (são réplicas em cerâmica de um artefato paleolítico), mas cada uma tem uma placa de identificação com uma coordenada geográfica (latitude e longitude) distinta. Nenhuma delas, aliás, refere-se ao local de descoberta/coleta do artefato. Se a obra fosse desmontada e as peças levadas às suas respectivas coordenadas, ganhariam status de totem ou marcação "Moscheta passou por aqui"; plotadas em mapa, transformar-se-iam em nós de uma linha, dando a ver o percurso. Extensivamente, só isso significariam. Mas essa linha registrada no mapa esconderia o tempo do percurso, a duração das paradas, a intensidade da experiência do artista no enfrentamento com o lugar. Comumente, na cartografia escolar, essas variáveis subjetivas só são "permitidas" nos chamados mapas mentais. Nos demais, somente objetividades são aceitáveis. É possível, sim, como faz Moscheta e como fazem vários usuários de mapas virtuais, abrir o mapa para que comportem subjetividades. Por que, então, insistimos nessas distinções entre mapas convencionais e mapas mentais como se tratasse de hierarquias de mapas (o segundo como "pré-mapa" ou "desenho cartográfico")?

Da obra "Atacama: 28.04-06.05/2012" podemos também desdobrar uma série de perguntas à cartografia escolar. Mas ficaremos com algumas: o que significaria em nossas estruturas de pensamento a respeito do espacial criar mapas não por adição, mas por apagamento? Quando criamos mapas a partir de uma folha em branco, que clichês de mapas já estão presentes lá? De que parte de nosso repertório cultural vieram essas imagens-clichê de mapas? Da cultura escolar, muito provavelmente. Portanto, como poderíamos produzir novas culturas de mapa na escola, que trabalhem na limpeza da tela em branco, no apagamento de elementos que já preenchem o imaginário sobre o que são imagens cartográficas, na desrepresentação, de modo a permitir a emergência de outros modos de imaginar o espaço?

\section{Desaudiovisualizar}

Marcelo Moscheta mantém com o audiovisual uma relação ambígua.

Acho que o vídeo tem esse apelo, que é um apelo de você ser pego pelo negócio e você sentir que... que você é levado a filmar! Você fala: "eu preciso registrar isso, é um momento único".

Eu não tenho a segurança ainda de trabalhar na linguagem do vídeo. Eu sei usá-la como documento, então muitas vezes a uso documentando essas ações, 
mas não me vejo ainda trabalhando com vídeo como um videoartista, ou usando a narrativa, usando roteiro. ${ }^{18}$

No entanto, já expôs obras realizadas nessa linguagem, como em "Hinc Sunt Leones", exibido na exposição "Terra Incognita"19: "Todas as vezes que mostrei esse vídeo [...] eu forrei o chão com grama, uma coisa integrada com o espaço" ${ }^{20}$, fazendo com que a projeção videográfica compusesse uma obra instalativa, não se configurando, na perspectiva do artista, como uma obra em vídeo.

Nesse texto gostaríamos de apontar essa ambiguidade ${ }^{21}$ como força criadora nas conexões que Moscheta estabelece com as câmeras de captura de imagens, sejam fotográficas ou videográficas. Focaremos na Exposição Norte, já citada acima, mais especificamente nas obras Maré (2009) ${ }^{22}$ e Atlântida.

Ambas as obras compuseram a referida exposição, apesar de Maré (Figura 7) ser uma obra anterior e não estar relacionada à viagem ao Polo Norte. Ao referir-se a essa obra Moscheta diz:

São projetores de slides; a imagem é puramente estática mas todo o sistema balança, assim como as imagens projetadas. Acho que aí está o embrião de uma linguagem, de uma imagem em movimento mas que é formalizado num trabalho totalmente instalativo, não tem nada de vídeo aí. ${ }^{23}$

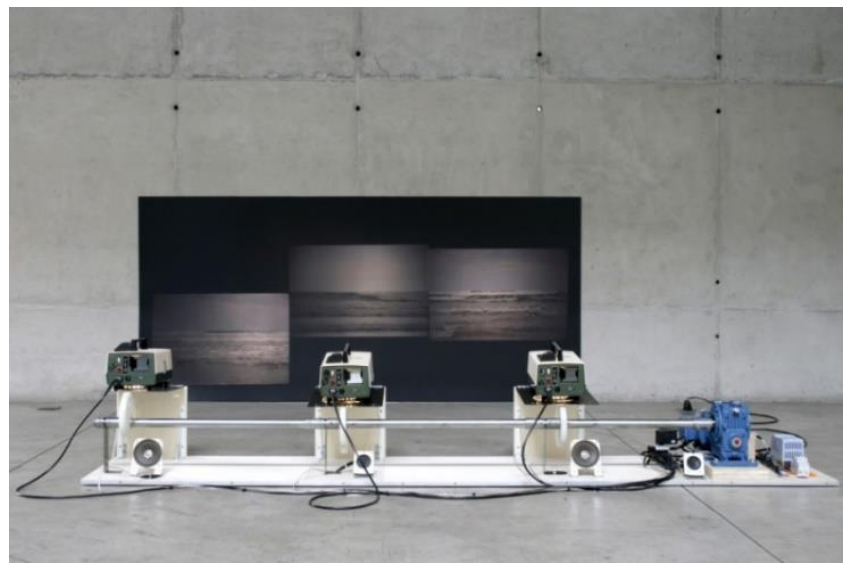

Figura 7 - Fonte: http://www.marcelomoscheta.art.br/tide-vers-1-3

As imagens projetadas são sequências de fotografias que estão em movimento: oscilam verticalmente umas em relação às outras, em velocidades distintas. A conjugação do movimento vertical diferenciado com a sequência fotográfica, que altera todo o tempo a visualidade do que é visto, coloca o espectador diante de um "sistema de imagens em movimento audiovisual" (Figura 8). Esse sistema mimetiza a oscilação oceânica das marés ao

\footnotetext{
18 Trechos da entrevista realizada por Gisele Girardi e Wenceslao Machado de Oliveira Júnior, em 25 de outubro de 2013, no ateliê do artista em Campinas-SP.

${ }^{19} \mathrm{http}: / /$ www.marcelomoscheta.art.br/terra-incognita.

${ }^{20}$ Trecho da entrevista realizada por Gisele Girardi e Wenceslao Machado de Oliveira Júnior, em 25 de outubro de 2013, no ateliê do artista em Campinas-SP.

21 “Acho que de certa forma meus trabalhos todos têm, sempre tiveram, um fator que é o da ambiguidade. É sempre assim: é, mas poderia também ser outra coisa. Ou então é mas não é, sabe, essas tensões que existem que podem enganar o observador e jogar o cara para outro lado". Trecho da entrevista realizada por Gisele Girardi e Wenceslao Machado de Oliveira Júnior, em 25 de outubro de 2013, no ateliê do artista em Campinas-SP.

${ }^{22}$ Link para entrevista em que a obra é apresentada pelo próprio artista, disponível em: 〈https://vimeo.com/58539606>.

${ }^{23}$ Trecho da entrevista realizada por Gisele Girardi e Wenceslao Machado de Oliveira Júnior, em 25 de outubro de 2013, no ateliê do artista em Campinas-SP.
} 
mesmo tempo que brinca com as experiências cinematográfica e videográfica fazendo-as escapar do habitual, na medida mesma que o movimento das imagens não se encontra no interior de um quadro fixo, mas num todo movente que, a despeito de não ser vídeo ou filme, provoca experiências audiovisuais.

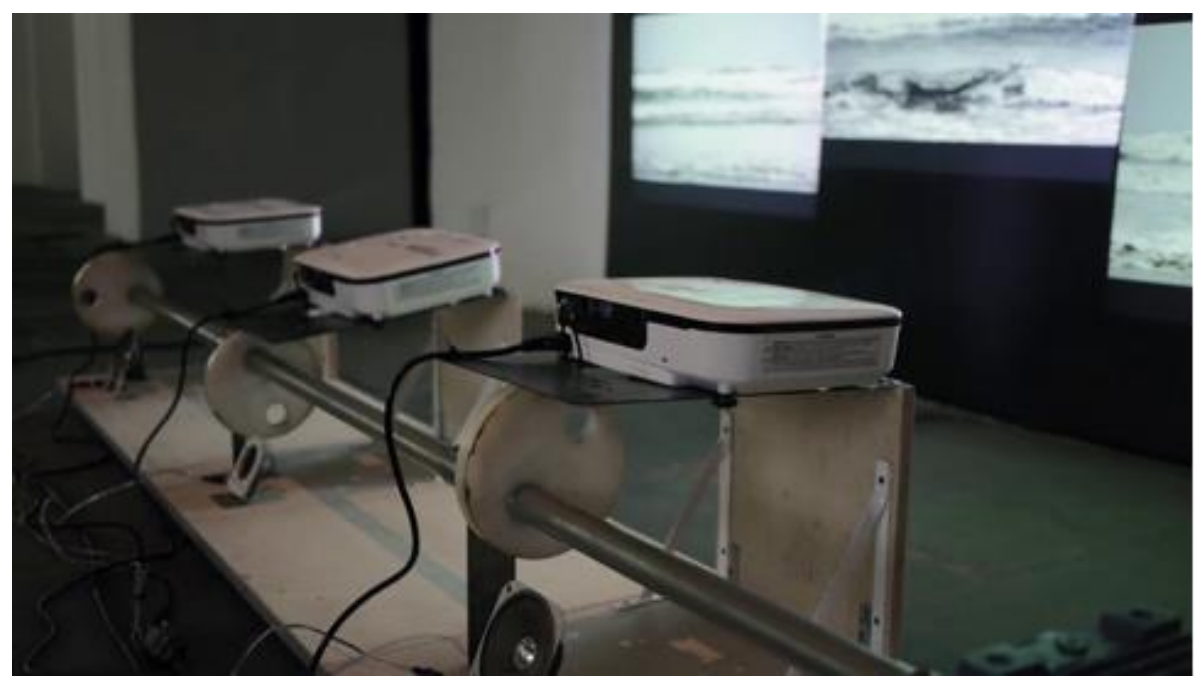

Figura 8 - Fonte: Frame de vídeo, disponível em https://vimeo.com/marcelomoscheta

A obra Atlântida (Figuras 9 e 10) ) $^{24}$ também não foi produzida a partir de imagens originalmente audiovisuais. Assim como Maré, Atlântida tem sob sua experiência de audiovisualidade um conjunto de fotografias tiradas pelo artista na "cidade fantasma" de Pyramiden, no arquipélago Svalbard, durante a residência artística lá realizada em 2011.

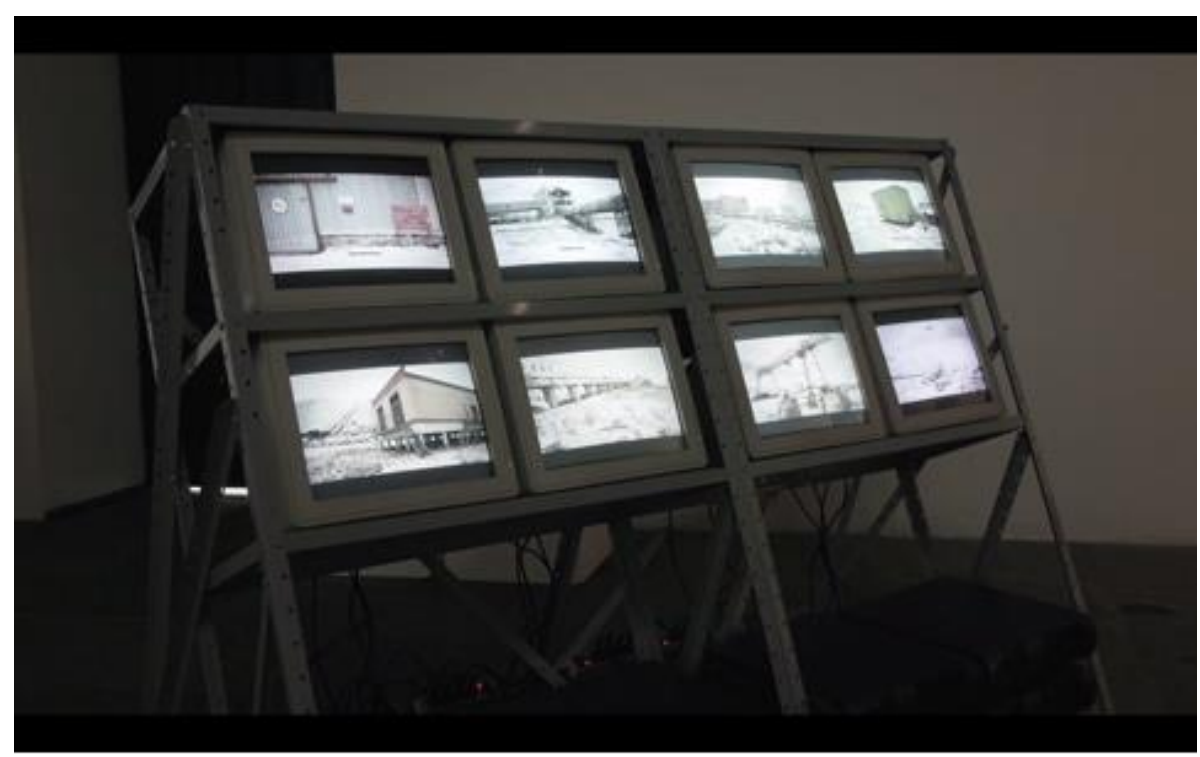

Figura 9 - Fonte: Frame de vídeo, disponível em https://vimeo.com/marcelomoscheta

\footnotetext{
${ }^{24}$ Link para entrevista em que a obra é apresentada pelo próprio artista, disponível em: 〈https://vimeo.com/58391866>.
} 


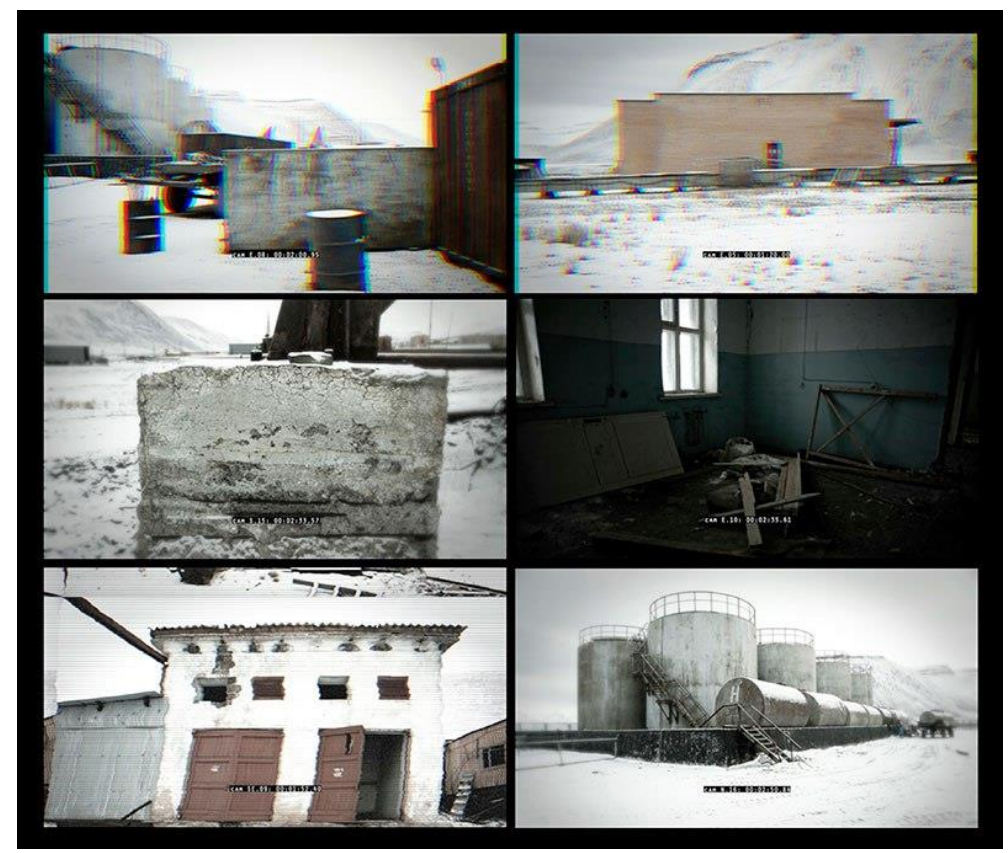

Figura 10 - Fonte: http://casaclaudia.abril.com.br/profissionais/masp-apresenta-exposicao-com-grandes-nomesda-fotografia/

As palavras do artista são indicadoras de como a obra se configura num vão aberto em meio à linguagem audiovisual, escapando a ela ao mesmo tempo que a expande, justamente por não se pautar pelas formas habituais dessa linguagem.

Atlântida é uma videoinstalação onde oito canais de vídeo são criados para poder imitar uma câmera de segurança que foi deixada numa cidade abandonada. Não se vê nenhuma pessoa transitando, não se vê nenhum movimento a não ser o movimento natural da precariedade das câmeras. $\mathrm{O}$ trabalho todo é falso, porque são monitores antigos de tevê, os computadores são antigos também; não são vídeos, são fotos sequenciadas com efeitos de vídeo por cima. ${ }^{25}$

Eu sequenciei fotos e, usando efeitos do Final Cut, coloquei movimentos de segurança; imitando-as, coloquei um counter embaixo. Só um counter embaixo aplicado a uma fotografia já transforma aquela fotografia em vídeo. ${ }^{26}$

O sentido de registro das imagens em vídeo é alcançado através da fotografia, bem como de todo um conjunto de materiais e formas antigos (atravessados por modernos softwares), os quais dobram sobre as imagens temporalidades e espacialidades múltiplas, forçando o registro a entrar em devir, a escapar de si próprio ao situá-lo em meio a diversos "entre": entre presente e passado e futuro, entre Pyramiden e Atlântida, entre ficção e realidade, entre real e imaginário, entre submerso e emerso, entre fotografia e vídeo, entre registro e criação... Cada "entre" implicando metamorfoses na zona de vizinhança ali criada, cada parte devindo outra desde dentro de si mesma, desdobrada de si em meio ao contágio de elementos da outra parte.

\footnotetext{
${ }^{25}$ Disponível em: 〈https://vimeo.com/58391866>.

${ }^{26}$ Trecho da entrevista realizada por Gisele Girardi e Wenceslao Machado de Oliveira Júnior, em 25 de outubro de 2013, no ateliê do artista em Campinas-SP.
} 
Devir não é atingir uma forma (identificação, imitação, Mimese), mas encontrar a zona de vizinhança, de indiscernibilidade ou de indiferenciação tal que já não seja possível distinguir-se de uma mulher, de $u m$ animal ou de uma molécula [de uma fotografia, de $u m$ vídeo, de $u m a$ cidade...]: não imprecisos nem gerais, mas imprevistos, não-preexistentes, tanto menos determinados numa forma quanto se singularizam numa população (DELEUZE, 1997, p. 11).

$\mathrm{Na}$ "população" dos registros em imagens, a obra Atlântida devém desregistro audiovisual, pois inventa uma nova forma de realizar esse registro, ampliando, portanto, sua potencialidade ao transfazê-lo em outro. Essa maneira de desregistrar um lugar faz fugir as formas preexistentes de sentido dados às imagens ali captadas: presente que devém passado, Pyramiden que devém Atlântida, realidade que devém ficção, fotografia que devém vídeo, etc. ao mesmo tempo que o inverso é também verdadeiro: passado que devém presente, Atlântida que devém Pyramiden, ficção que devém realidade, vídeo que devém fotografia, etc. Criando zonas de indiscernibilidade que engendram potências de arte e de pensamento, ou melhor dizendo, de arte-pensamento, essa obra nos aponta outras potencialidades para fotografias e vídeos em suas conexões com práticas geográficas e educativas, potencialidades essas que nos parecem tanto mais interessantes quanto mais essas estratégias artísticas possam ampliar as estratégias expressivas dos estudantes ao facilitar criarem produções - obras de arte? - que alcancem dobrar sobre as imagens o intensivo que tiver atravessado seus corpos no contato com o extensivo do lugar.

$\mathrm{Na}$ entrevista já citada acima em que fala sobre Atlântida, Marcelo Moscheta deixa entrever o intensivo que o atravessou em Pyramiden:

Cenário de hecatombe nuclear, onde você entra num espaço e tem a sensação de que todo mundo morreu e só você ficou. [...] Ao mesmo tempo existia uma ternura de poder ver uma fotografia na parede de uma criança que morou ali, de poder ver um talher do lado de um prato de uma pessoa que saiu correndo e deixou tudo na mesa como devia estar... ${ }^{27}$

Sensações e imaginações reverberadas no contato com as trajetórias heterogêneas que configuram aquela cidade abandonada. Contato que foi também contágio, uma vez que as forças que emergiram dessas trajetórias - vazio, talheres, fotografia na parede... - afetaram o corpo do artista fazendo com que ele extraísse daquele lugar imagens fotográficas que não o representam em si mesmo, exterior ao artista, mas sim o desrepresentam ao dobrar sobre ele as sensações e imaginações que passaram a existir naquele corpo no momento mesmo do contato. Um exemplo de como a arte pode ampliar um lugar e de como um lugar não é sempre o mesmo se o pensarmos a partir das singularidades gestadas em cada encontro entre um lugar e uma nova trajetória de vida, que vem encontrar-se com as que já o compõem em sua heterogeneidade.

Ao buscar dar expressão para essas sensações e imaginações, as fotografias de Moscheta foram forçadas a entrarem em devir vídeo para expressarem o lugar em alguns de seus infinitos devires possíveis, aqueles que se configuraram na zona de vizinhança indiferenciada entre artista e lugar.

É angustiante olhar as imagens e não saber o que fazer com elas. Na verdade, eu soube o que fazer, elas viraram outras coisas, elas se transformaram em

\footnotetext{
${ }^{27}$ Trecho da entrevista com o artista sobre a obra. Disponível em: 〈https://vimeo.com/58391866>.
} 
outras coisas - esse metamorfosear em outro -, mas o vídeo, a captação desse material bruto não virou um vídeo no sentido tradicional como a gente conhece, na linguagem do vídeo. ${ }^{28}$

Nesse sentido, parece-nos que a linguagem audiovisual se intromete nas ações de Moscheta como uma possibilidade de criação, ainda que não se estabeleça no significado de registro. Ao contrário, as imagens audiovisuais criadas por esse artista nas obras acima comentadas, oscilam, resistem a se estabilizarem como mera representação de algo, forçam as fronteiras do documento, arrastando o "conteúdo" dessas imagens (as formas e traços que ficaram impressos nas fotografias e vídeos) para as margens da linguagem-obra de arte, tornando esse "conteúdo registrado" mais explicitamente atravessado por aquilo que não constitui esse "conteúdo" como forma visível, mas como forças que atuam através dele (sensações, imaginações, arrepios, sonhos, linguagens, tecnologias...).

É nesse sentido que o vídeo não se encontra como material expressivo explícito na Exposição Norte, mas sim como força, a um só tempo, desestabilizadora e amparadora de muitas das obras. Em grande medida isso se deve por ele ter sido um amparo - o suporte de linguagem - na produção de registros imagéticos do encontro entre artista e lugar-Polo Norte, mas também, e principalmente, por ser uma força que provoca desvios nestes mesmos registros, retirando-os dessa condição única de documento do real espacial. Na exposição Norte o vídeo pulsa, atravessa transversalmente aquilo que ali se expressa, pois tanto ele desaparece em outras linguagens, metamorfoseado em fotografia ou desenhos que trazem fragmentos das capturas registros - feitas em vídeo (enquadramentos, ângulos, cores, contrastes, transparências, ideias... mas nunca movimentos, como no caso das obras "Miragem" ou "À deriva"29), quanto o vídeo aparece como artifício para dar movimento àquilo que, como registro fotográfico, não registrava movimento algum, como no caso da obra "Atlântida".

Também em "Atlântida" notamos a estética-política dos vídeos de vigilância, tanto na pouca definição das imagens quanto na disposição das muitas telas numa espécie de grande tela panóptica que daria a ver todos os cantos daquele lugar. A estética-política dessa obra atua como um acaso manipulado, fazendo com que os espectadores sejam lançados a estabelecer aproximações entre a obra - um conjunto de telas próximas que podem ser vistas numa única mirada a certa distância - e as práticas de vigilância dos lugares contemporâneos. A brincadeira irônica da obra se radicaliza no fato de que Pyramiden é desabitada, portanto não havendo humanos a serem vigiados e, justo por isso, desloca a experiência da obra para as proximidades das observações feitas em outros planetas ou em lugares inexistentes ou, melhor dizendo, existentes somente em histórias e imaginações, sem provas científicas dessa existência. "Atlântida" seria, portanto, um desregistro, algo que, nos termos de Manoel de Barros, arrasta uma coisa para seus deslimites, abrindo outros possíveis nessa coisa.

Podemos desdobrar dessa obra algumas perguntas à geografia e à geografia escolar: não seria assim também para os lugares que a ciência geográfica diz existir e comprova com inúmeros registros - entre eles, fotográficos e videográficos - a sua "existência existente"? Ou será que a insistente repetição das imagens de um lugar - sempre o Cristo Redentor ou a Torre Eiffel - buscam exatamente dar a sensação de que eles, a despeito de qualquer transformação, são sempre os mesmos?

\footnotetext{
${ }^{28}$ Trecho da entrevista realizada por Gisele Girardi e Wenceslao Machado de Oliveira Júnior, em 25 de outubro de 2013, no ateliê do artista em Campinas-SP.

${ }^{29}$ Alguns dos registros em vídeo feitos pelo artista no Pólo Norte podem ser vistos durante as entrevistas de Marcelo Moscheta sobre essas obras em: https://vimeo.com/58542694 e https://vimeo.com/58389033.
} 


\section{Palavras finais}

Buscamos nesse artigo apontar elementos que perpassam a geografia de Marcelo Moscheta quando coisa, indicar com que geografias ele compõe e que geografias ele produz. Poderíamos concluir que são geografias inventadas e elas o são. Mas qual geografia não o é?

Poderíamos dizer que essas invenções de Moscheta têm força de geografia porque grafam o espaço de alguma maneira. Poderíamos mesmo dizer que a principal maneira dele grafar o espaço é científica: uma ciência rasurada em suas pretensões de verdade assentadas na precisão, na documentação, nas provas irrefutáveis de que algo é, de que um lugar existe tal qual o podemos ver em obras cartográficas e audiovisuais.

Nas obras aqui trazidas para compor nossa escrita essas mesmas obras cartográficas e audiovisuais escapam dessa pretensão de verdade científica sem escapar da ciência. Essa última permanece nas obras como força que as constitui de múltiplas maneiras, mas não as conforma em sentidos estáveis e previsíveis. Ao contrário, os elementos da ciência nelas presentes são também elementos que as potencializam em suas pretensões de afetar o público da arte: propõem a ele que acredite ser possível, através delas, acessar aqueles lugares... e assim ocorre... mas não somente ao lugar enquanto coisa objetiva, mapeável e filmável, mas sobretudo ao lugar enquanto coisa grafada, mapeada e filmada.

Entendemos que as geografias desse artista quando coisa têm força para transtornar hábitos educativos na medida mesma em que elas fazem com que os lugares se desviem de seus modos habituais de configurar os percursos e pensamentos geográficos, forçando-os à deriva ao colocá-los à mercê das linguagens que os atravessam e os grafam de múltiplas maneiras, tomando-os como coisas: matérias vivas em suas próprias representações desrepresentadas. Isso se torna ainda mais potente quando Moscheta compõe suas geografias justamente com as linguagens que normalmente dão o suporte para que esses mesmos lugares existam enquanto tais, em si, descolados das trajetórias-forças humanas e inumanas que neles habitam e se metamorfoseiam constantemente.

Ao aproximar improváveis coisas, o artista evidencia-se como coisa entre elas: inventa geografias e desafia alunos e professores a também inventá-las, "pois que inventar aumenta o mundo" (Manoel de Barros, 2010, p. 362).

\section{Referências}

BARROS, M. de. Retrato do artista quando coisa. In: BARROS, Manoel de. Poesia completa. São Paulo: Leya, 2010.

BUENAVENTURA, J. Marcelo Moscheta 1.000 Km, 10.000 Anos. ArtNexus Magazine Review, Bogotá, n. 90, v. 12, 2013. p. 136. Disponível em: <http://www.marcelomoscheta.art.br/MarceloMoscheta-1000-km-10000-anos>.

DELEUZE, G.; GUATTARI, F. O que é a filosofia? Rio de Janeiro: Editora 34. 1992.

DELEUZE, G. Conversações: 1972-1990. Rio de Janeiro: Ed. 34, 1992.

. Crítica e Clínica. Rio de Janeiro: Ed. 34, 1997.

. Francis Bacon: lógica da sensação. Rio de Janeiro: Zahar, 2007. 
GIRARDI, G. Entre obras de arte e cartografia geográfica: intercessores. In: COLÓQUIO IBÉRICO DE CARTOGRAFIA, 14, 2014, Guimarães. Actas do XIV Colóquio Ibérico de Cartografia. Guimarães: APG/UMinho, 2014. v. 1. p. 488-493.

GIRARDI, Gisele. Horror vacui: cartografia e imaginações espaciais. In: COLÓQUIO INTERNACIONAL 'A EDUCAÇÃO PELAS IMAGENS E SUAS GEOGRAFIAS', 3, 2013, Vitória. Anais do III CIEIG. Vitória: Ed. da Geografia, v. 1, 2013. p. 1-8.

MASSEY, D. Pelo espaço: uma nova política da espacialidade. Rio de Janeiro: Bertrand Brasil, 2008.

MIYADA, P. Do que nomeia os saberes de Marcelo Moscheta. In: Catálogo da exposição Carbono 14, realizada na SIM Galeria em Curitiba, 2015. Disponível em: <http://www.marcelomoscheta.art.br/Do-Que-Nomeia-Os-Saberes-De-Marcelo-Moscheta>.

SOUZA, E. L. L. de. Manoel de Barros: a poética do deslimite. Rio de Janeiro: 7Letras, 2010.

TALA, A. 1.000 km, 10.000 anos. Texto para a exposição na Galeria Leme, 2013. Disponível em: <http://www.marcelomoscheta.art.br/1000-km-10000-anos $>$. 